\title{
Business response to COVID-19 impact: Effectiveness analysis in South Africa
}

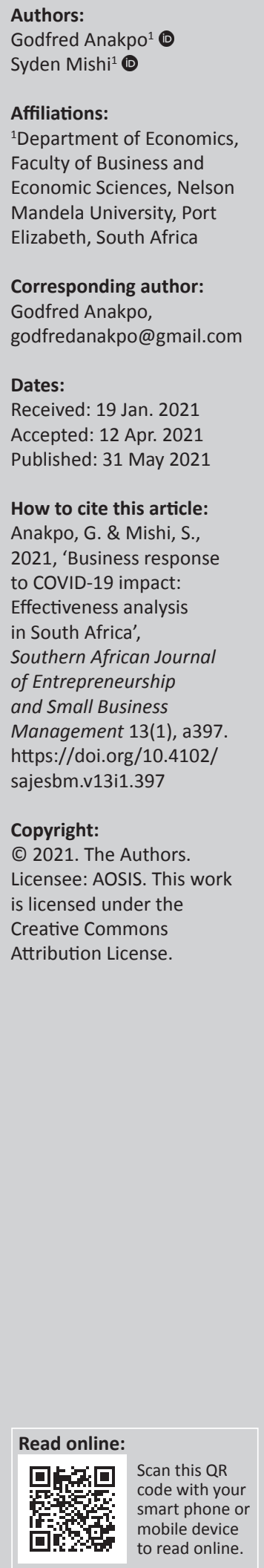

Background: Following the outbreak of Coronavirus disease 2019 (COVID-19), many businesses have put out measures to counter the impact of the outbreak and its related reactions from economic actors (individuals, authorities and other businesses) on their business operations. However, nearly no empirical studies or reports have been carried out to investigate the effectiveness of those measures.

Aim: This study aimed at examining the effectiveness of business response measures to COVID-19 impact on business outcome.

Setting: This study focused on businesses that are value-added tax (VAT) registered.

Methods: A cross-sectional survey design was used. The authors applied logistic regression technique to analyse the effectiveness of business response measures on business outcome.

Results: The authors found evidence that business responses such as virtual connection, innovative e-commerce and increasing working hours are more effective business responses, whilst decreasing work hours, laying off workers temporarily and ordinary e-commerce are less effective measures against the impact of the outbreak. Furthermore, business characteristics such as industry type (e.g. 'agriculture, hunting, forestry and fishing' and 'electricity, gas and water supply') are more resilient to COVID-19 shock, whilst pure export market and small businesses, secondary and tertiary, are significantly less resilient.

Conclusions: Firstly, the study shows that some business responses are more effective in remediating the adverse impact of COVID-19 and therefore recommends policy intervention and industrial actions to promote them. Secondly, it is also recommended that financial bailout and/or Internet infrastructure and domestic support for small and export businesses could make them more resilient to the adverse impact of the outbreak.

Keywords: business response; COVID-19 impact; outbreak; effectiveness analysis; South Africa.

\section{Introduction}

The outbreak of Coronavirus disease 2019 (COVID-19) has caused major economic shock and abnormalised business operation. Globally, it was estimated that each additional month the COVID-19 crises cost $2.5 \%-3 \%$ of global gross domestic product (GDP), up to over $15 \%$ fall in a country's GDP (Fernandes 2020), and this trend is expected to continue to the future as a result of (1) the forced reduction in the production of goods and services because of lockdown restriction, (2) reduction in household demand for goods and services (e.g. reduction in tourism because of travel and movement restriction), (3) disruption of global production and supply chains and (4) the impact of uncertainty on business investment (Arndt et al. 2020). The outbreak of COVID-19 has far-reaching effects, leading to about 'half a million firms at risk of collapse' (AmankwahAmoa, Khan \& Wood 2020), accelerating unemployment by causing 24.3 million job losses (Ozili \& Arun 2020). This has significantly reduced investor's confidence (OECD Interim Economic Assessment 2020), posed significant short-run logistical challenges and severely disrupted goods demand (Juergensen, Guimón \& Narula 2020).

South Africa is by no means exempted from the adverse impact of the COVID-19 pandemic. For instance, South Africa recorded a negative growth rate of $-5.4 \%$ (Arndt et al. 2020; Boumans, Link \& Sauer 2020), closure of many firms and a decrease in employment from $57 \%$ to $38 \%$ (Ranchhod \& Daniels 2020). This affects the overall business turnover of companies and investors. To minimise the adverse impact of COVID-19 crises, many businesses have put forth measures to counter the impact of the outbreak and its related reactions from economic actors (individuals, authorities and other businesses) on their business operations. 
Several business responses have been applied since the outbreak of COVID-19 and subsequent lockdown restriction. For instance, globally the use of virtual connection and e-commerce approach to counter the potential losses increased by $74 \%$ (Bhatti et al. 2020), whilst others also engaged in modified business operation temporarily laying off workers. Kumar et al. (2020) documented that few companies altered methods of production and diversified the production of goods and services to cope with the adverse effect. Statistics South Africa (2020) reported that most businesses adopted response measures such as changing method of producing goods and services, decreasing maintenance cost and investing in equipment as risk aversion measure. Furthermore, Van Assche and Lundan (2020) reported that virtual connection and conferencing are likely to positively impact multinational enterprises in the 'new normal' and Pencavel (2015) on the other hand found that increasing the number of hours of work is more likely to increase productivity, ceteris paribus. Empirical literature on the effectiveness of COVID-19 response is mainly limited to governmental response measures (such as COVID-19 relief funds, cash transfer, grant or bailout for some businesses).

Firstly, almost no empirical studies have sought to investigate the effectiveness of business response measures (COVID-19 impact) on business outcome in the existing literature. Secondly, literature on COVID-19 impacts and effectiveness of response are either limited to government COVID-19 relief or are mainly descriptive in nature without rigorous analysis. This article seeks to addresses these gaps in the literature.

This study contributes to the literature and shape policy direction by investigating the effectiveness of business response to COVID-19 impact on the business outcome (turnover) in the context of South Africa with a more rigorous analysis. It is imperative to identify best practices as this and related shocks are inevitable in the future, which businessmen and policymakers ought to be equipped with.

\section{Literature review}

There is a body of literature on COVID-19 and its profound impact on economic and business activities (Bartik et al. 2020; Boumans et al. 2020; Fairlie 2020; Juergensen et al. 2020; Kumar et al. 2020). For instance, in their descriptive analysis of over 5800 small businesses in North America, Bartik et al. (2020) found that the outbreak of the pandemic with its lockdown and movement restrictions resulted in the closure of over $43 \%$ business temporarily or permanently, laid off about $40 \%$ of company's employees, leading to decreased work hours and low productivity (Pencavel 2015), whilst about $75 \%$ of small businesses risked losing business within 2 months of the outbreak because of insufficient funds. Similarly, Juergensen et al. (2020) conducted impact analysis of COVID-19 crisis and policy response on the European small- and medium-sized enterprises (SMEs) in the manufacturing sector and found that most of the SMEs face significant logistical challenges at least in the short run, in addition to severe disruptions in demand (Arndt et al. 2020) because of border closure, although the severity of this impact has differed across SMEs, which are important for inclusive growth (Bhorat et al. 2018). They also argued that in the longer term, there will be different challenges and opportunities depending on the type of SME. Kumar et al. (2020) also reported that the global production and supply chain system of goods is mostly disrupted because of movement restrictions, border closures resulting from the outbreak of COVID-19. Using literature review approach, Amankwah-Amoa et al. (2020) reported that pandemic precipitates business failures and has sped up the reconfiguration of the relationship between states and markets, deepened the divide between those with and without political connections, whilst experiential knowledge and skills resources may be both an advantage and a burden. Furthermore, in his descriptive analysis, Fairlie (2020) documented that African-American businesses were hit hard experiencing a $41 \%$ drop, dropped Latinx business owners by $32 \%$, Asian business owners by $26 \%$, about $36 \%$ losses in immigrant business and female-owned businesses dropped by $25 \%$.

The impact experience of businesses because of COVID-19 crisis is not different in Africa, which is often characterised with fragile fundamentals and weaker business resilience to shock (Fatoki 2018). Ozili (2020) showed from his descriptive analysis that COVID-19 had negative effects on oil industry (through decline in oil prices) in Nigeria, which in turn affects other business operation along oil supply chain. Other literature that highlights the negative impacts of COVID-19 on business operation and outcome includes Khambule (2020) and Kumar et al. (2020). A few studies have however, investigated some business response measures to remediate the impact of COVID-19 crisis.

Limited literature exists on the response to COVID-19 impact and its effectiveness. For instance, in his analysis of the effectiveness of governmental intervention such as cash transfer, relief packages and grant during COVID-19, Khambule (2020) revealed that whilst the South African government's R500 billion social and economic relief is an effective response measure to stimulate economic activities, it does little to protect those in the informal economy, and thus further actions are needed for SME's economic development (Razumovskaia et al. 2020). Concerning COVID-19 energy sector responses in Africa, Akrofi and Antwi (2020) found that only three countries (Nigeria, Kenya and Burkina Faso) had specific interventions for renewables and that interventions were mostly fiscal or financial and short term, with medium- to long-term measures often broad without being specific to the energy sector. In their business policy studies, Van Assche and Lundan (2020) reported that virtual connection (conferencing) is likely to positively impact multinational enterprises in the 'new normal' (Moodley \& Morris 2004; Overgaard et al. 2020; Wymbs 2000). 
In addition, in their studies on the impact of COVID-19 on small businesses, Bartik et al. (2020) reported that small business predicts business outcomes amidst pandemic because of their financial fragility. Pencavel (2015) applied linear regression model to investigate the productivity of output (e.g. business output) and found that increasing the number of hours of work and worker (through employment) is associated with higher output and business turnover and vice versa. However, there is a paucity of literature on the effectiveness of business response measures with regard to the impact of COVID-19 on business outcome. Furthermore, the existing studies fail to go beyond descriptive measures to a more rigorous analysis on the effectiveness of business response measures to the impact of COVID-19.

To address this gap, this article is guided by the decision-making theory which states that under risk and uncertainty, individuals and, derivatively, business entities make rational choices through a process or sequence of activities involving stages of problem recognition, search for information, definition of alternatives and the selection of options, which are advantageous given an uncertain environment to affect outcome (Ahmed \& Omotunde 2012; Edwards 1954; Turpin \& Marais 2004). Thus, the business response decisions to COVID-19 crisis are to remediate the effect of the pandemic, which affects business outcome.

\section{Research methods and design}

The analysis in this article used data from Statistics South Africa COVID-19 Business impact survey design. This survey was conducted in May 2020 to provide close to real-time economic insight into the impact of the COVID-19 pandemic on 1079 VAT-registered businesses by using a rapid response survey. The survey data contain vital characteristics of the business operations, including industry types, market and the size. In this survey, nine industries were covered: agriculture, hunting, forestry and fishing; mining and quarrying; manufacturing; electricity, gas and water supply; construction; trade, transport, storage and communication; real estate and other business services; community, social and personal services; and others. Export and import market information was also provided. In the survey, respondents were asked to provide annual turnover prior to the outbreak and if their business turnover was below, within or above normal during the level 4 lockdown period because of COVID-19, and this was also captured in the data. Furthermore, information on business responses to remediate the impact of COVID-19 and its related outcome on business turnover was also collected. This encompasses the use of virtual connection, changing production methods, producing different goods and services, laying off workers temporarily, maintenance cost management, e-commerce, using new approach to reach customers, and investing in equipment, amongst others.
Using Janky (2001) model with slight modification, business outcome is defined as a function of response decision, as follows:

BusOutcome $_{i}=\beta_{O}+\beta_{j} \sum_{j=1}^{13} \operatorname{Resp}_{j i}+\gamma X+\varepsilon i i$

[Eqn 1]

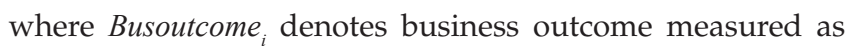
one if business turnover is at least within normal (15.7\%), zero if it is below normal (84.3\%), Resp $p_{i i}$ is a vector of business response measures which is one if one falls in the following categories: use of virtual connection, changing production methods, producing different goods and services, laying off workers temporarily, maintenance cost management, e-commerce, using new approach to reach customers, investing in equipment, zero if otherwise. The variable $i$ represents businesses, $j$ is the number of response measures and $X$ is a vector of covariates, which captures business characteristics such as industry types (which is measured as if a business falls within the following industries: manufacturing, agriculture, hunting, forestry and fishing; community, social and personal services; construction; electricity, gas and water supply; transport, storage and communication; mining quarry, and real estate and other business services, and zero if otherwise), business size (measured as one if small business, zero if otherwise) and market (one if a business is purely export driven, zero otherwise). In the second model, with the same analytical procedure, the industry type was collapsed into primary, secondary and tertiary sectors (see Tables 1,2 and 3 ). $\beta_{j}$ is the parameters of interest that measure the effectiveness of business response to COVID-19 impact, and $\varepsilon$ is the error term. In this analysis, maximum likelihood (ML) is used as the estimator for the logistic regression model.

It is also worth noting that businesses that are in economic crises and financial distress may often take actions such as laying off workers, reducing working hours and vice versa (Allan \& Loseby 1993). Thus, reversal causality, a potential

TABLE 1: A summary statistics: Industry types and sectors.

\begin{tabular}{lccc}
\hline Variable & $\begin{array}{c}\text { Number of } \\
\text { businesses }\end{array}$ & $\%$ & Frequency \\
\hline Industry & 177 & 16.4 & - \\
Agriculture, hunting, forestry and fishing & 27 & 2.5 & - \\
Mining and quarrying & 226 & 20.9 & - \\
Manufacturing & 14 & 1.3 & - \\
Electricity, gas and water supply & 61 & 5.7 & - \\
Construction & 185 & 17.1 & - \\
Trade & 106 & 9.8 & - \\
Transport, storage and communication & 126 & 11.7 & - \\
Real estate and other business services & 116 & 10.8 & - \\
Community, social and personal services & 41 & 3.8 & - \\
Other & 1079 & 100 & - \\
Total & & & \\
Sectors & - & 19.7 & 204 \\
Primary sector (e.g. agriculture and mining) & - & 29.0 & 301 \\
Secondary sector (e.g. manufacturing & & & \\
and construction) & - & 51.3 & 533 \\
Tertiary sector (service related) & - & 100 & 1038 \\
\hline Total & & & \\
\hline
\end{tabular}


issue of endogeneity, may sometimes be expected. However, the data used for the analysis in this study were responses provided by the respondents as measures aimed at coping or improving the business operations, turnover, amidst the COVID-19 outbreak and this rules out the reversal causality. To validate this, a diagnostic test that approximates endogeneity test was conducted by regressing potential endogenous variables, such as laying off workers and increasing and decreasing working hours on the residuals from the given model (see Table 4). The results were all insignificant, confirming that endogeneity was not a problem.

\section{Results}

Tables 1-3 provide summary statistics on key variables of interest, such as industrial composition and sectors into which the businesses belong, business response measures, types of market, business size and turnover.

Tables $1-3$ show that about $20.9 \%$ of businesses are in the manufacturing industry, whilst $17.1 \%$ and $16.4 \%$ are in the trade and agriculture, hunting, forestry and fishing

TABLE 2: Summary statistics: Business response measures.

\begin{tabular}{lcc}
\hline Strategic responses or measures & Frequency & $\mathbf{\%}$ \\
\hline Virtual connection & 413 & 38.2 \\
Increase working hours & 50 & 4.6 \\
Lay off workers temporarily & 277 & 25.7 \\
No measures & 217 & 20.1 \\
Altered production method & 161 & 14.9 \\
Altered good and services provided & 166 & 15.4 \\
Discontinued good and services & 157 & 14.5 \\
Adopt new ways to sell & 286 & 26.5 \\
Decrease working hours & 377 & 34.9 \\
E-commerce & 127 & 11.8 \\
Investing in equipment & 26 & 2.4 \\
Increase maintenance cost & 61 & 5.7 \\
Decrease maintenance cost & 178 & 16.5 \\
\hline Total & 1079 & 100
\end{tabular}

TABLE 3: Summary statistics: Market, business size and turnover.

\begin{tabular}{lcc}
\hline Variable & Frequency & $\mathbf{\%}$ \\
\hline Market & & \\
Export & 416 & 44.7 \\
Import & 515 & 54.3 \\
Total & 931 & 100 \\
Business size & & \\
Micro - Small business (R0 - R30millions) & 517 & 47.87 \\
Medium - Large (> R30million) & 563 & 52.13 \\
Total & 1080 & 100 \\
Business turnover & & \\
Within or above normal & 169 & 15.7 \\
Below normal & 905 & 84.3 \\
Total & 1074 & 100 \\
\hline
\end{tabular}

TABLE 4: Results of preliminary test for endogeneity.

\begin{tabular}{lccc}
\hline $\begin{array}{l}\text { Endogeneity } \\
\text { test results }\end{array}$ & $\begin{array}{c}\text { Laying off } \\
\text { workers* }\end{array}$ & $\begin{array}{c}\text { Increasing } \\
\text { working hours** }\end{array}$ & $\begin{array}{c}\text { Decreasing } \\
\text { working hours*** }\end{array}$ \\
\hline Predicted errors & -0.0503 & -0.0447 & 0.0101 \\
Standard errors & 0.0684 & 0.1324 & 0.0602 \\
$p$-value & $<0.462$ & $<0.735$ & $<0.866$ \\
\hline
\end{tabular}

$*, p<0.462 ; * *, p<0.735 ; * * *, p<0.866$ businesses, respectively. This is followed by real estate and other business services (11.7\%); community, social and personal services (10.8\%); transport, storage and communication $(9.8 \%)$; mining and quarrying $(2.5 \%)$; and electricity, gas and water supply (1.3\%). These industries were broadly categorised into three sectors, namely, primary sector $(19.7 \%)$, secondary sector $(29.0 \%)$ and tertiary sector (51.3\%). This sectoral distribution reflects similar report on the economic sectors in South Africa in 2019 (Plecher 2020). Concerning business response measures, Table 2 reports that about $38.2 \%$ of businesses resorted to the use of virtual connection for business transaction because of the lockdown restriction to remediate the impact on business turnover. Other businesses adopted measures such as decreasing working hours (34.9\%), adopting new ways to sell (26.5), laying off workers $(25.7 \%)$, decreasing maintenance cost (16.5), changing methods of producing goods and services $(15.4 \%)$, altering goods and services provided (14.5\%), e-commerce (11.8) investing in equipment and increasing working hours (4.6\%). Furthermore, Table 3 shows that about $44.7 \%$ businesses deal with some form of export, and about $47.9 \%$ are micro and small businesses. In addition, $84.3 \%$ participants responded that business turnover was below the normal following the lockdown restriction because of COVID-19 outbreak.

Table 5 displays results on the effectiveness of business response to COVID-19 impact on business outcome (business turnover). The table documents results on two marginal effects: the first marginal effect includes reports on industry-type characteristics of the business, whilst the second marginal effect categorises industries into primary, secondary and tertiary sectors. The results show that businesses that use virtual connection and innovative e-commerce (interaction of new ways of contacting and selling to customers with e-commerce) in business transaction are, respectively, $4.5 \%$ and $13.6 \%$ more likely to keep their operation at least within the normal turnover. Results also show that businesses that increase working hours are $7.4 \%$ more likely to be at least within their normal business turnover. It is also apparent from the table that the normal e-commerce is $11.2 \%$ less likely to keep the business turnover at least within the normal operation. Table 5 also shows that business characteristics such as industry types, market and size are important predictors of business turnover amidst COVID-19 crises. Results indicate that businesses in agriculture, hunting, forestry and fishing, and electricity, gas and water supply are $10.3 \%$ and $17.8 \%$, respectively, more likely to be at least within the business turnover (amidst COVID-19), which implies more resilience to the shock of the outbreak. In addition, export-driven businesses are $8.8 \%$ less likely to operate at least within the normal turnover. Other export businesses with local market potential or alternative transaction are $10.2 \%$ more likely to withstand the pandemic shock and remain within the normal operation. Data in Table 5 also indicate that small businesses are $11.3 \%$ less likely to operate within the normal business turnover. Results in Table 5 further reveal that the secondary and tertiary sectors are 
TABLE 5: Effectiveness of business response to the coronavirus disease 2019 on the business outcome (turnover).

\begin{tabular}{|c|c|c|c|c|}
\hline \multirow[t]{2}{*}{ Variables } & \multicolumn{2}{|c|}{ Marginal effects } & \multicolumn{2}{|c|}{ Marginal effects } \\
\hline & Coefficients & Standard errors & Coefficients & Standard errors \\
\hline Virtual connection & $0.0453 * *$ & 0.0194 & $0.0554 * * *$ & 0.0196 \\
\hline $\begin{array}{l}\text { Innovative e-commerce (interaction of } \\
\text { e-commerce and new ways of selling) }\end{array}$ & $0.1359 * *$ & 0.0622 & $0.1351^{* *}$ & 0.0655 \\
\hline Decrease working hours & $-0.0831 * * *$ & 0.0208 & $-0.0919 * * *$ & 0.0213 \\
\hline Increase working hours & $0.0744 * *$ & 0.03229 & $0.0827^{* * *}$ & 0.0341 \\
\hline Laying off workers & $-0.1424 * * *$ & 0.027 & $-0.1542 * * *$ & 0.028 \\
\hline Altered production method & -0.0043 & 0.0264 & 0.0047 & 0.0272 \\
\hline Altered goods and services provided & $-0.0492 *$ & 0.0274 & $-0.0562 *$ & 0.029 \\
\hline New ways to interact and sell & -0.0309 & 0.022 & -0.0278 & 0.023 \\
\hline E-commerce & $-0.1116 * *$ & 0.0521 & $-0.119 * *$ & 0.0551 \\
\hline Investing in equipment & 0.0306 & 0.0523 & 0.0259 & 0.0543 \\
\hline Increase maintenance cost & 0.0121 & 0.0334 & 0.007 & 0.0359 \\
\hline Decrease maintenance cost & $-0.0568 * *$ & 0.0268 & $-0.0555 * *$ & 0.0279 \\
\hline Community, social and personal services & 0.0205 & 0.0302 & - & - \\
\hline Construction & $-0.1223 *$ & 0.0668 & - & - \\
\hline Electricity, gas and water supply & $0.1777 * * *$ & 0.0606 & - & - \\
\hline Manufacturing & 0.0036 & 0.0309 & - & - \\
\hline Trade & -0.0286 & 0.0323 & - & - \\
\hline Transport, storage and communication & 0.042 & 0.0311 & - & - \\
\hline Mining quarry & -0.0398 & 0.0616 & - & - \\
\hline Secondary sector & - & - & $-0.0662 * *$ & 0.0259 \\
\hline Tertiary sector & - & - & $-0.0647 * *$ & 0.0225 \\
\hline Pure export & $-0.0880 * * *$ & 0.0215 & $-0.0921 * * *$ & 0.0219 \\
\hline Small business & $-0.1135 * * *$ & 0.0191 & $-0.1091 * * *$ & 0.0192 \\
\hline Pseudo $\mathrm{R}^{2}$ & 0.2088 & - & 0.1755 & - \\
\hline Probability > chi-square & 0.0000 & - & 0.0000 & - \\
\hline Observation & 1074 & - & 1074 & - \\
\hline
\end{tabular}

$*, p<0.1 ; * *, p<0.05 ; * * *, p<0.01$.

$6.6 \%$ and $6.5 \%$ less likely to be at least within the normal range of their business turnover as compared with the primary sector, such as agriculture-related business and mining, which are relatively less affected by the COVID-19 restriction.

\section{Discussion}

The significant positive relationship between business response measures such as the use of virtual connection and innovative e-commerce and business outcome is not surprising because the lockdown restriction following the outbreak of COVID-19 coupled with social distancing regulation forced many businesses to use virtual or Internet means to reach customers and business partners in South Africa. For instance, following the pronouncement of lockdown in South Africa because of COVID-19 pandemic, there was significant spike in Internet demand and traffic to an average of $27.5 \%(15 \%-40 \%)$ within 1 month (SEACOM 2020). This finding reinforces a report by Overgaard et al. (2020) that virtual way of business has turned to be part of a 'new normal' to maintain survival of businesses (i.e. to keep business transaction in the normal range).

The findings of this study also reveal that business response measures such as increasing working hours are more likely to increases productivity and business outcome. The lockdown restriction causes the demand for certain essential goods (e.g. sanitary goods) to increase and therefore it is within expectation that could positively contribute to keeping business normal. Secondly, time is also required to explore coping strategies through research to remediate the adverse consequences and therefore it is not surprising that increasing working hours is positively associated with high business turnover. On the contrary, responses such as decreasing working hours are negatively associated with business turnover. This implies that businesses that decrease working hours are less like to keep their business at least within the normal operation. This also confirms Pencavel's (2015) finding that increasing hours of work predicts high productivity and vice versa.

It is however interesting to find that whilst innovative e-commerce (interaction of new ways of contacting and selling to customers with e-commerce) is positively related to business turnover at least within the normal range, the normal e-commerce is less likely to keep the business turnover at least within the normal operation.

This finding goes against common positive expectation (Wymbs 2000) arguably because the economic shock created by the COVID-19 crises may have spillover effect across sectors and business operations, which may require a more tailored approach to e-commerce operation to increase business turnover. This could also be partly attributed to the fact that a significant proportion of e-commerce businesses are export driven. 
Consequently, the lockdown restriction and subsequent border closure could make online goods delivery across borders difficult and may negatively affect business in the short term. Concerning e-commerce in South Africa, Moodley and Morris (2004) reported that business marketing strategy such as e-commerce has only marginally changed business activities and trading behaviour between international buyers and sellers in garment industry.

The findings also suggest that the effectiveness of business response measures on business outcomes depends on some characteristics, such as industry types, type of market and business size. For instance, businesses in industries such as agriculture, hunting, forestry and fishing and electricity, gas and water supply show to be more resilient to the shock of the outbreak. Concerning this, Arndt et al. (2020) reported that production of electricity and water were part of essential goods and services continued during the lockdown period therefore, there was no disruption from the supply side. The authors also documented that agriculture activities are less affected as compared with other businesses, which predominantly involves social contact. Thus, it is expected that business turnover is within the normal or above the normal.

Export-driven businesses are significantly negatively associated with business turnover. This finding is within expectation as many countries outside South Africa also implement border closure and other containment measures in response to COVID-19 outbreak; thus, the factory shutdowns, general delays in shipment and reduction in global demand are likely to affect export-driven businesses. The fall in export demand depends on the magnitude and duration of restrictions and border closure. According to a report by Arndt et al. (2020), export demand is expected to fall by $40 \%-75 \%$ except for agricultural export, which is expected to remain fairly the same. This finding is also consistent with that of Juergensen et al. (2020) and Kumar et al. (2020), who concluded that the pandemic has caused significant logistical challenges in the short run and severe disruptions in demand for goods and global production and supply chain system for SMEs.

Furthermore, small businesses are not resilient to shock such as COVID-19 crises as shown in Table 5. This finding is consistent with that of Bartik et al. (2020) who documented that small businesses are financially fragile and therefore more prone to the adverse impacts of COVID-19 pandemic. Small, medium and microenterprises (SMMEs) have been identified as a key component to advancing inclusive growth and development in South Africa (Bhorat et al. 2018), so this effect, by implication, poses major threat to South Africa's economic health. The findings also reveal that the secondary and tertiary sectors are less resilient as compared with the primary sector. This finding reflects the general economic outlook of South Africa where tertiary sector (services) remains the leading sector yet, the country recorded a negative growth rate of 5.4\% (Arndt et al. 2020; Boumans et al. 2020).

\section{Conclusion}

The outbreak of COVID-19 and its related reactions from economic actors (individuals, authorities and other businesses) have major adverse impact on business operations. This triggers several responses from businesses to counter the effects. However, nearly no empirical studies or reports have been carried out to investigate the effectiveness of those measures. In this article, we applied logistic regression technique (using Statistics South Africa COVID-19 Business impact survey data) to examine the effectiveness of business response in remediating COVID-19 impact on business outcome (turnover) in South Africa. We found evidence that business responses such as virtual connection, innovative e-commerce and increasing working hours are significantly more likely to keep business operation against the shock of the outbreak and therefore are more effective business responses. However, responses such as decreasing working hours, laying off workers temporarily and ordinary e-commerce are significantly less likely to be effective against the impact of the outbreak. We also found that business characteristics such as industry type, size and market (export vs. local) predict business resilience to COVID-19 shock; industry types such as 'agriculture, hunting, forestry and fishing' and 'electricity, gas and water supply' are significantly more resilient to COVID-19 shock. Furthermore, pure export market and small businesses, secondary and tertiary, are significantly less resilient to the COVID-19 shock.

\section{Implications and recommendations}

Based on the findings of this study, we recommend policy intervention and industrial actions that promote virtual connection and innovative e-commerce for business operations. The findings imply that policy interventions need to be sensitive and tailored to the different types of SMEs in terms of industry, sector, market type and size rather than adopting a one-size-fits-all approach and should not only focus on business survival in the short term but building resilience for long-term operation through innovation. It is also recommended that financial bailout and/or Internet infrastructure and domestic support for small and export businesses could also make them more resilient to the adverse impact of the outbreak.

\section{Limitations}

The authors acknowledge that the analysis in this article is based on self-reported data from the business operators in the survey; therefore, it is likely that the respondents might either underestimate or overestimate their business outcomes amidst COVID-19 outbreak. The qualitative nature of the data also limits detailed quantitative analysis (e.g. production function modelling for labour and capital change on output), and future research should include that.

\section{Acknowledgements Competing interests}

The authors have declared that no competing interests exist. 


\section{Authors' contributions}

G.A. was responsible for conceptualisation, methodology, formal analysis, investigation and original draft writing. S.M. was responsible for supervision, writing reviews and editing and suggestions that enhanced the conceptualisation, methodology and write-up of this article.

\section{Ethical considerations}

This article followed all ethical standards for research without direct contact with human or animal subjects.

\section{Funding information}

Funding for this study was provided by the National Research Foundation of South Africa (Grant number: 121890) and Nelson Mandela University through Vice Chancellor funds.

\section{Data availability}

Data used in this study can be accessed via http://www. statssa.gov.za/publications/Report-00-80-01/Report-00-8001May2020.pdf.

\section{Disclaimer}

The views and opinions expressed in this article are those of the authors and do not necessarily reflect the official policy or position of any affiliated agency of the authors.

\section{References}

Ahmed, M.T. \& Omotunde, H., 2012, 'Theories and strategies of good decision making', International Journal of Scientific \& Technology Research 1(10), 51-54.

Akrofi, M.M. \& Antwi, S.H., 2020, 'COVID-19 energy sector responses in Africa: A review of preliminary government interventions', Energy Research \& Socia Science 68, 101681. https://doi.org/10.1016/j.erss.2020.101681

Allan, P. \& Loseby, P.H., 1993, 'No-layoff policies and corporate financial performance SAM', Advanced Management Journal 58(1), 44-49.

Amankwah-Amoah, J., Khan, Z. \& Wood, G., 2020, 'COVID-19 and business failures: The paradoxes of experience, scale, and scope for theory and practice', European Management Journal 39(2), 179-184. https://doi.org/10.1016/j.emj.2020.09.002

Arndt, C., Davies, R., Gabriel, S., Harris, L., Makrelov, K., Modise, B., Robinson, S. Simbanegavi, W., Van Seventer, D. \& Anderson, L., 2020, Impact of Covid-19 on the South African economy. Southern Africa - Towards inclusive economic development: Working Paper 111, viewed 25 September 2020 from https://satied.wider.unu.edu/sites/default/files/pdf/SA-TIED-WP-111.pdf

Bartik, A.W., Bertrand, M., Cullen, Z., Glaeser, E.L., Luca, M. \& Stanton, C., 2020 'The impact of COVID-19 on small business outcomes and expectations' Proceedings of the National Academy of Sciences 117(30), 17656-17666. https:// doi.org/10.1073/pnas.2006991117

Bhatti, A., Akram, H., Basit, H.M., Khan, A.U., Raza, S.M. \& Naqvi, M.B., 2020, 'E-commerce trends during COVID-19 Pandemic', International Journal of Future Generation Communication and Networking 13(2), 1449-1452.

Bhorat, H., Asmal, Z., Lilenstein, K. \& Van der Zee, K., 2018, 'SMMES in South Africa: Understanding the Constraints on Growth and performance', Development Policy Research Unit Working Paper 201802, Development Policy Research Unit: University of Cape Town, Cape Town.
Boumans, D., Link, S. \& Sauer, S., 2020, COVID-19: The world economy needs a lifelinebut which one? EconPol Europe Policy Brief 27, viewed n.d., from https://www. econpol.eu/publications/policy_brief_27

Edwards, W., 1954, 'The theory of decision making', Psychological Bulletin 51(4), 380. https://doi.org/10.1037/h0053870

Fairlie, R.W., 2020, The impact of COVID-19 on small business owners: Evidence of early-stage losses from the April 2020 current population survey (No. w27309), National Bureau of Economic Research, viewed 15 October 2020 from https:// onlinelibrary.wiley.com/doi/full/10.1111/jems.12400

Fatoki, O., 2018, 'The impact of entrepreneurial resilience on the success of small and medium enterprises in South Africa', Sustainability 10(7), 2527. https://doi. org/10.3390/su10072527

Fernandes, N., 2020, Economic effects of coronavirus outbreak (COVID-19) on the world economy, viewed 20 September 2020, from https://papers.ssrn.com/sol3/ papers.cfm?abstract_id $=3557504$

Janky, B., 2001, 'Rational choice theory in sociology and quantitative empirical research: A survey', Review of Sociology 7(1), 21-34. https://doi.org/10.1556/ RevSoc.7.2001.1.2

Juergensen, J., Guimón, J. \& Narula, R., 2020, 'European SMEs amidst the COVID-19 crisis: Assessing impact and policy responses', Journal of Industrial and Business Economics 47(3), 499-510. https://doi.org/10.1007/s40812-020-00169-4

Khambule, I., 2020, 'The effects of COVID-19 on the South African informal economy: Limits and pitfalls of government's response', Loyola Journal of Social Sciences 34(1), 95-109.

Kumar, A., Luthra, S., Mangla, S.K. \& Kazançoğlu, Y., 2020, 'COVID-19 impact on sustainable production and operations management', Sustainable Operations and Computers 1, 1-7. https://doi.org/10.1016/j.susoc.2020.06.001

Moodley, S. \& Morris, M., 2004, 'Does e-commerce fulfil its promise for developing country (South African) garment export producers?', Oxford Development Studies 32(2), 155-178. https://doi.org/10.1080/13600810410001699939

Organisation for Economic Co-operation and Development (OECD) Interim Economic Assessment, 2020, Coronavirus: The world economy at risk, Organisation for Economic Co-operation and Development, Paris.

Overgaard, S., Neyret, P., Günther, K.P. \& Felländer-Tsai, L., 2020, 'Virtual congresses - The new normal? EFORT 2020 re-worked: The virtual EFORT congress (VEC) from 28 to 30 October 2020 is coming this way!', EFORT Open Reviews 5(8), 519-521. https://doi.org/10.1302/2058-5241.5.200300

Ozili, P.K., 2020, 'COVID-19 pandemic and economic crisis: the Nigerian experience and structural causes', Journal of Economic and Administrative Sciences, vol. ahead-of-print, no. ahead-of-print. https://doi.org/10.1108/JEAS-05-2020-0074

Ozili, P.K. \& Arun, T., 2020, Spillover of COVID-19: Impact on the global economy, viewed 12 October 2020 from https://www.papers.ssrn.com/sol3/papers. cfm?abstract_id $=3562570$

Pencavel, J., 2015, 'The productivity of working hours', The Economic Journal 125(589), 2052-2076. https://doi.org/10.1111/ecoj.12166

Plecher, H., 2020, Gross domestic product (GDP) distribution across economic sectors South Africa 2019, viewed 04 October 2020, from https://www.statista.com/ statistics/371233/south-africa-gdp-distribution-across-economic-sectors/.

Ranchhod, V. \& Daniels, R.C., 2020, Labour market dynamics in South Africa in the time of COVID-19: Evidence from wave 1 of the NIDS-CRAM survey, NIDS-CRAM Working Paper, Southern Africa, Labour and Development Research Unit: University of Cape Town, Cape Town.

Razumovskaia, E., Yuzvovich, L., Kniazeva, E., Klimenko, M. \& Shelyakin, V., 2020, 'The effectiveness of Russian Government Policy to support SMEs in the COVID-19 pandemic', Journal of Open Innovation: Technology, Market, and Complexity 6(4), 160. https://doi.org/10.3390/joitmc6040160

SEACOM, 2020, How much Internet traffic in South Africa has increased due to the coronavirus, viewed 28 September 2020, from https://www.seacom.co.za/mediacentre/how-much-internet-traffic-south-africa-has-increased-due-coronavirus/

Statistics South Africa (SATS SA), 2020, Business impact survey of the COVID-19 pandemic in South Africa, Embargoed until: 21 April 2020, 10:00, viewed n.d. from http://www.statssa.gov.za/publications/Report-00-80-01/Report-00-80-01 April2020.pdf

Turpin, S.M. \& Marais, M.A., 2004, 'Decision-making: Theory and practice', ORiON 20(2), 143-160. https://doi.org/10.5784/20-2-12

Van Assche, A. \& Lundan, S., 2020, 'From the editor: COVID-19 and International business policy', Journal of International Business Policy 3, 273-279. https://doi. org/10.1057/s42214-020-00065-7

Wymbs, C., 2000, 'How e-commerce is transforming and Internationalizing service industries', Journal of Services Marketing 14(6), 463-477. https://doi.org/10.1108/ 08876040010347598 